\title{
"INSTINTO DE NACIONALIDADE" NA IMPRENSA LIBERAL
}

\author{
Atilio Bergamini \\ Universidade Estadual de Campinas / Fapesp \\ Campinas, SP, Brasil
}

\begin{abstract}
Resumo: O artigo analisa a circulação do ensaio "Notícia da atual literatura brasileira: instinto de nacionalidade" (1873), de Machado de Assis, em jornais liberais. Parte-se de um comentário sobre o ensaio machadiano para alargando o enquadramento de análise - evidenciar relações entre seus critérios de avaliação de romances e alguns temas daqueles jornais, principalmente a desaprovação da literatura francesa coetânea, além do anseio por uma crítica literária que corrigisse erros dos escritores e sugerisse tendências. Esses dois momentos do artigo - sobre a circulação e sobre os critérios - amparam discussões a respeito de algumas mistificações das práticas machadianas de escrita.
\end{abstract}

Palavras-chave: "Instinto de nacionalidade"; imprensa liberal; romance.

\section{"Instinto de nacionalidade" in the liberal press}

\begin{abstract}
The present article purposes to analyse the circulation in liberal newspapers of Machado de Assis' essay "Notícia da atual literatura brasileira: instinto de nacionalidade" (1873). The article starts with a comment on "Notícia", then it tries to extend its framework of analysis, highlighting relations between some criteria used by Machado on his criticism of novels and some themes explored in the liberal newspapers. These two moments of the article - on the circulation and on the criteria - raise discussions on some mystification of Machado's writing practices.
\end{abstract}

Keywords: "Instinto de nacionalidade"; liberal press; novels.

1.

Machado de Assis organizou "Notícia da atual literatura brasileira - instinto de nacionalidade" em cinco partes (apresentação do problema, romance, poesia, teatro, língua). A primeira atestava "o fato atual": certo "instinto de nacionalidade", um "desejo" - presente "até na opinião" - "de criar uma literatura mais independente". "Até na" demarca a posição crítica do articulista em relação ao alegado fato. Fica sugerido que a opinião, ao menos ela, poderia passar ao largo do instinto de nacionalidade. Porém: 
Reconhecido o instinto de nacionalidade que se manifesta nas obras destes últimos tempos, conviria examinar se possuímos todas as condições e motivos históricos de uma nacionalidade literária; esta investigação (ponto de divergência entre literatos), além de superior às minhas forças, daria em resultado levar-me longe dos limites deste escrito. Meu principal objeto é atestar o fato atual; ora, o fato é o instinto de que falei, o geral desejo de criar uma literatura mais independente. ${ }^{1}$

O trecho, com grifo meu, indica que, para Machado, recorria, da parte de literatos, certa racionalização a respeito da literatura brasileira. Essa racionalização tinha alguma efetividade, mas caberia auscultar as condições e motivos históricos de uma nacionalidade literária. De tal tarefa, Machado se afasta, indicando, a tempo, discrepâncias entre o que literatos esperavam da literatura e o que as possibilidades concretas do fazer literário nas instituições e práticas daquele período permitiam. Investigar as condições e motivos históricos do objeto do instinto-desejo resultaria no esclarecimento dos literatos a respeito da impossibilidade, naquele momento, de uma "literatura mais independente". Mas independente do quê? De quem?

Ao longo da argumentação, Machado figura uma tradição originada por José Basílio da Gama e Santa Rita Durão, continuada por Gonçalves Dias, Porto-Alegre e Magalhães, e cultivada pelos contemporâneos; enfim, uma continuidade "interna" com a obrigação de lidar com influxos "externos", mormente portugueses e franceses. A reflexão desestabiliza perspectivas de recorte nacional para tirar consequências do caráter globalizado da circulação de impressos e das avaliações a respeito deles. Literatura, na ótica machadiana, implica um interesse geral, humano, auscultado no tempo e lugar do escritor. A esse respeito, interessa, tanto quanto a representação machadiana do problema, a série de indícios formais, temáticos e tipográficos disseminados na fatura de "Notícia da atual literatura brasileira": ser impresso em Nova Iorque, circular no Brasil, problematizar um público atraído por romances franceses contemporâneos, elogiar a imitação de franceses mais antigos, demarcar autonomia relativa em relação a Portugal e mesmo remeter a um crítico escocês citado numa

\footnotetext{
${ }^{1}$ ASSIS, Machado de. Obra completa em quatro volumes. Rio de Janeiro: Nova Aguilar 2008. v. 3. p. 1204. A partir de agora referido como "OC, III", seguido do número da página.
} 
revista francesa (retomaremos alguns desses pontos a seguir). O problema posto, ainda para nós, é a construção de uma perspectiva crítica no capitalismo editorial globalizado.

Por isso, o ponto de vista elogioso em relação a Basílio da Gama e Durão - por terem eles apontado os primeiros traços da fisionomia literária nacional - falharia ao enfatizar um critério anacrônico de avaliação artística, além de limitar a imaginação frente a isso tudo. Como e por que se deveria avaliar Tomás Antônio Gonzaga partindo de exigências políticas e literárias posteriores à independência?

Sob essa ótica, entende-se por qual razão Machado retomava a questão "da história e os costumes indianos", então algo resolvida. Tal história e tais costumes constituiriam parte do legado deixado pela literatura brasileira para a literatura universal. Parte, somente. Os escritores, aliás, teriam compreendido isso e estavam doravante - informava Machado - empenhados em estudar os "costumes civilizados", ainda que a natureza americana os atraísse e desafiasse.

O romance, sobretudo, apoderou-se de todos esses elementos de invenção, a que devemos, entre outros, os livros dos Srs. Bernardo Guimarães, que brilhante e ingenuamente nos pinta os costumes da região em que nasceu, J. de Alencar, Macedo, Sílvio Dinarte (Escragnolle Taunay), Franklin Távora, e alguns mais. ${ }^{2}$

O problema ganhava feição mais evidente quando Machado opinava ser erro os críticos procurarem "espírito nacional" somente em obras com "assunto local", com "assunto que lhe oferece a sua [do escritor] região". O espírito nacional não consistia na escolha de assuntos locais. Consistia - se nossa hipótese está correta - na construção de uma perspectiva artística capaz de estabelecer relações problematizadoras com as condições de produção intelectual no Brasil, entre elas, o "instinto de nacionalidade".

Não há dúvida que uma literatura, sobretudo uma literatura nascente, deve principalmente alimentar-se dos assuntos que lhe oferece a sua região; mas não estabeleçamos doutrinas tão absolutas que a empobreçam. $\mathrm{O}$ que se deve exigir do escritor antes de tudo, é certo sentimento íntimo, que o torne homem do seu tempo e do seu país,

\footnotetext{
${ }^{2}$ OC, III, p. 1205.
} 
ainda quando trate de assuntos remotos no tempo e no espaço. Um notável crítico da França, analisando há tempos um escritor escocês, Masson, com muito acerto dizia que do mesmo modo que se podia ser bretão sem falar sempre do tojo, assim Masson era bem escocês, sem dizer palavra do cardo, e explicava o dito acrescentando que havia nele um scotticismo interior, diverso e melhor do que se fora apenas superficial. ${ }^{3}$

Esse trecho condensa vetores de relações complexas e ambivalentes, em meio às quais Machado estava constituindo sua posição. $\mathrm{O}$ crítico francês é Louis Étienne. "Masson" é David Masson, um crítico escocês. A expressão "scotticisme interieur" apareceu em artigo de Étienne na Revue des Deux Mondes: "La critique contemporaine en Anglaterre. II. David Masson".

Contrapor assuntos da "região" a assuntos remotos parece chancelar a autoridade da revista francesa e do crítico francês para estabelecer desaprovações: o que Étienne expressara, a "crítica nacional" estaria longe de praticar. Além disso, cada extremo da contraposição coordena paradigmas de explicação de como o espírito nacional se faria presente na literatura e na crítica. Ou seja, a região combina superficialidade, ilusão, "nacionalidade de vocabulário", enquanto o remoto chancelado pela revista e pelo crítico francês - articula o sublime, o simples, o sentimento íntimo, o humano em geral.

O reconhecimento da autoridade do crítico francês instiga ainda mais se identificarmos que, para Machado (pelo menos desde 1858), um dos entraves da produção literária nacional - ao lado da presença "perniciosa" de certos romances franceses (ainda quando esses corrompessem somente o público) - era a falta de uma

\footnotetext{
${ }^{3}$ OC, III, p. 1205-1206.

4 Revue des Deux Mondes, 15 de agosto, ano 36, v. 64, 1866, p. 901-926. Disponível em http://gallica.bnf.fr. Acessado em: 20/08/2013. "[...] Le scotticisme de M. Masson [...] n'est pas seulement de surface. Comme on peut étre un parfait Breton sans parler toujurs de l'ajonc e de la bruyère, M. Masson est bom Écossais sans dire un mot du chardon. [...] Il a le scotticisme intérieur, celui qui avec un tour de pensée Écossais s'applique à des sujets nationaux, mieux encore à des sujets humains et généraux" (p. 905). Tradução minha: "[...] O escocismo de Masson [...] não é somente de superfície. Como é possível ser um perfeito bretão sem falar sempre do tojo e das urzes, Masson é bom escocês sem dizer uma palavra do cardo. [...] Ele possui o escocismo interior, aquele que, com o molde do pensamento escocês, aplica-se nos assuntos nacionais e melhor ainda nos assuntos humanos e gerais".
} 
atividade crítica constante e criteriosa. ${ }^{5}$ Fica salientada a ambivalência: da França provêm bons exemplos (a Revue, além de Vitor Hugo, Gautier, Musset, Gozlan e Nerval), além de jorrarem dependência e decadência (ou seja, a decadência dos romances populares, muitos deles editados naquele ano de 1873 na "Biblioteca de Algibeira", pelo francês B. L. Garnier, a soldo de quem Machado escrevia desde 1864, no Jornal das Famílias).

O trecho em que a Revue aparece como argumento de autoridade trabalha portanto com uma das linhas centrais do ensaio - quando não com "a" linha central -, a saber, o chamado ao estabelecimento de uma crítica bem informada, fomentadora de um nacionalismo arejado pela investigação das condições do belo, pois estas fariam a literatura brasileira se inserir na cultura ocidental.

Se, objetivamente, faltava ao gênero romanesco uma crítica minuciosa e severa, além do enfrentamento da invasão francesa, em termos imanentes, Machado especificou três critérios para avalia-lo: a descrição (toques do sentimento, quadros da natureza e de costumes); a análise de paixões e caracteres; as tendências morais e políticas.

No que concernia à descrição e às tendências, o romance brasileiro era recomendável e instrutivo, principalmente por não se deixar contaminar pelas novidades francesas. Porém, Machado julgava a análise de paixões e caracteres "incompatível com nossa adolescência literária", "uma das partes mais difíceis do romance, e ao mesmo tempo das mais superiores. Naturalmente exige da parte do escritor dotes não vulgares de observação, que, ainda em literaturas mais adiantadas, não andam a rodo nem são a partilha do maior número". Ao comentar tendências morais e políticas, a maior qualidade de nossos romancistas, Machado lidava com fenômenos que iam da multiplicação da oferta de literatura pornográfica ou de sensação à proposta então consolidada de o romance revelar "a verdade". Discutir cuidadosamente o problema levaria a outro estudo, mas cabe assinalar que nosso ensaísta mesclou, entre outras possibilidades, uma crítica ao realismo - que, a exemplo de outros momentos do ensaio, dialogava com diversos artigos da Revue des Deux Mondes - e, consequentemente, uma

\footnotetext{
${ }^{5} \mathrm{O}$ tema da falta de crítica no periodismo brasileiro aparece no último parágrafo da introdução geral. Asserções parecidas reaparecem três vezes na seção sobre o romance e também na abertura da seção sobre poesia: "A ação da crítica seria sobretudo eficaz em relação à poesia".
} 
tentativa de estabelecer uma perspectiva crítica à expansão do que lhe parecia ser o conteúdo básico do capitalismo editorial, sobretudo francês: isto é, "dizer a verdade", propor-se como "razão".

Descrição (no sentido de estudo dos costumes), análise de paixões e caracteres, além de decoro (tanto moral, quanto na adequação da linguagem ao tema, ao "autor" etc.) constituíam, para o Machado de 1873, as "partes do romance", sendo a análise "uma das mais superiores". Depreende-se do conjunto de enunciados machadianos sobre o romance que um assunto ou tema deveria perpassar tais partes, dando-lhes unidade, ao mesmo tempo em que as partes contribuiriam para tornar o assunto multifacetado e complexo. ${ }^{6}$

Avaliar romances passava por reconstruir qual era seu assunto e entender se ele estava ou não estava composto pelas supostas partes do belo romanesco, se ele, desde uma perspectiva liberal, concretizava boas tendências morais e políticas. Por isso, não se podia avaliar romances sobretudo por critérios nacionalistas imediatos. Quem fazia isso, todavia? Quem, no ambiente intelectual fluminense, considerava como principal critério de avaliação de romances a "cor local"?

A resposta mais radical a essa pergunta é: ninguém. Dificilmente, encontraremos na imprensa posterior a 1870 uma resenha, escrita por intelectuais com um mínimo de impacto, avaliando bem um romance (ou qualquer obra literária) em primeiro lugar porque possuísse "cor local". Pelo contrário, desde os anos 1860, tornouse comum articulistas criticarem, por diversas razões, a ideia de cor local. ${ }^{7}$

\footnotetext{
${ }^{6}$ Exemplo de como Machado utilizava a noção de "assunto" (às vezes, "tema") para compreender romances está na resenha a respeito de Iracema. Quatro perguntas sintetizam esses critérios: 1) as personagens são tipos desenvolvidos, moralmente densos, e são construídas respeitando uma lógica moral, isto é, um sistema de valores próprios? 2) O estilo condiz com a voz que narra? 3) As ações e situações se relacionam com o assunto escolhido pelo escritor e o desenvolvem? 4) O livro contribui para o desenvolvimento das letras nacionais? Diante de Iracema, Machado respondeu positivamente a todas essas perguntas. As personagens são tipos, contribuindo para multifacetar e aprofundar o assunto (OC, III, p. 1115). Alencar teria evitado o "anacronismo moral": "O estilo do livro é como a linguagem daqueles povos: imagens e ideias, agrestes e pitorescas, respirando ainda as auras da montanha [...]" (OC, III, p. 1116). Os episódios, pela exteriorização do caráter das personagens, estão "ligados ao assunto principal" (OC, III, p. 1115): a fundação do Ceará, os amores de Iracema e Martim, o ódio das nações indígenas adversárias. Mesmo que o argumento provenha de crônicas históricas, ele é desenvolvido, antes de tudo, pelas exigências literárias do assunto. O livro é uma obra-prima, colaborando com o desenvolvimento da poesia americana (OC, III, p. 1116).

${ }^{7}$ Ver, para um exemplo, mais adiante, referência a Sotero dos Reis. Ver também: ZILBERMAN, Regina. Almeida Garrett e o cânone romântico. Via Atlântica, n. 1, março, 1997. p. 54-65.
} 
Se recuamos no tempo, todavia, a defesa naturalizada da cor local se torna comum. No artigo publicado em 1858, em A Marmota, "O passado, o presente e o futuro da literatura", era Machado quem argumentava faltar à poesia "uma cor local", "cunho puramente nacional". ${ }^{8}$ Tomás Antônio Gonzaga, por exemplo, teria um "caráter essencialmente europeu". Da mesma forma, Basílio da Gama teria escrito O Uraguai sem prestar as devidas contas ao aspecto nacional, já que "a poesia indígena, bárbara [...] não é nacional". 9

Pouco a pouco, desde então, Machado passou a considerar a figuração de "sentimentos morais" como fundamento estético de bons romances. ${ }^{10}$ Já em 1860, no Diário do Rio de Janeiro, elogiou um drama por praticar as regras e prescrições da arte, sem dispensar "as sutilezas da cor local". ${ }^{11}$ Nesse panorama, "Notícia" retomava os argumentos e a estrutura de "O passado, o presente e o futuro", porém reconsiderava o artigo de 1858 quanto à postura frente ao uso de motivos indígenas na literatura e quanto à questão da cor local. ${ }^{12}$ Ao rever a relevância desta questão, passou a enfatizar a "pessoa moral".

Parece, aliás, haver relação entre a contínua apropriação dos problemas concernentes a escrever e avaliar romances, a partir da segunda metade da década de 1860, e o declínio da legitimidade da ideia de cor local. No arco entre aqueles dois ensaios machadianos, o romance, como gênero, passou - do ponto de vista de Machado - de pouco praticado a gênero mais lido e mais praticado (ao lado da poesia lírica). ${ }^{13}$

\footnotetext{
${ }^{8}$ OC, III, p. 1003.

${ }^{9}$ Idem.

${ }^{10}$ Em crítica de 1863 ao livro Sombras e Luz, de um escritor português, B. Pinheiro, escreveu uma frase que, com variantes, é recorrente em boa parte de suas resenhas: "o autor" - refere-se a Pinheiro - "cuidou menos dos sentimentos morais dos seus personagens, para tratar miudamente das situações e dos fatos" (OC, III, p. 1060).

${ }^{11}$ Diário do Rio de Janeiro, 29/03/1860, p. 1.

${ }^{12}$ Cf. ZILBERMAN, Regina. Almeida Garrett e o cânone romântico, cit.

${ }^{13}$ Data de abril de 1858 o ensaio "Passado, presente e futuro da literatura", apresentado como "pequeno exame genérico de nossas letras". Então com dezenove anos, o ensaísta elaborou em A Marmota um diagnóstico a respeito da situação da literatura brasileira depois da Independência política. Machado se propôs a estudar "as três formas literárias essenciais: o romance, o drama e a poesia". Os dois primeiros, ele afirma, não vingavam, em parte pela "convivência perniciosa com os romances franceses". Se o drama não se desenvolvera entre nós, tampouco o teatro, a respeito do qual éramos um povo "parvo e pobretão entre as nações cultas". Segue-se uma crítica às traduções, à "inundação de peças francesas" (OC, III, p. 1002-1006).
} 
2.

"Notícia da atual literatura brasileira - Instinto de nacionalidade" foi publicado pela primeira vez em 24 de março de 1873, em O Novo Mundo, periódico brasileiro impresso em Nova Iorque e editado por José Carlos Rodrigues. Em carta de 22 de setembro de 1872, Rodrigues pediu a Machado um estudo sobre o caráter geral da literatura brasileira contemporânea, criticando boas e más tendências, "no aspecto literário e moral". Rodrigues mencionou o desejo de traduzir o ensaio para o inglês e prometeu pagar o "melhor que puder". ${ }^{14}$ Correspondência entre os dois indica que em dezembro o artigo estava quase pronto. ${ }^{15}$

Meses depois da publicação, em setembro, "Notícia" reapareceu no A Reforma, do Rio, e, em 4 e 5 de outubro, no A Reforma, de Porto Alegre. Nessas oportunidades, os editores modificaram o título: em negrito e destacado, aparecia "Literatura brasileira". Em itálico e com fonte reduzida, "Instinto de nacionalidade". Em vida de Machado, houve ainda republicações em O Novo Mundo (abril de 1879) e A Semana (17 de setembro e $1^{\mathrm{o}}$ de outubro de 1887). ${ }^{16}$

Há traços comuns entre os jornais em que "Notícia" circulou. O Novo Mundo, A Reforma e A Semana se apresentavam como periódicos liberais (republicanos, abolicionistas, "progressistas"). Este último, fundado em 1885, foi comandado pelo abolicionista e republicano Valentim Magalhães. Sobre $O$ Novo Mundo, comentaremos a seguir. A Reforma circulava desde 1869 no Rio de Janeiro e, de acordo com Nelson Werneck Sodré, em 1873 tornou-se um dos jornais mais lidos da Corte, ao entrar nos

\footnotetext{
${ }^{14}$ ROUANET, Sergio Paulo (Org. e Coord.). Correspondência de Machado de Assis: tomo II, 1870-1889. Rio de Janeiro: Academia Brasileira de Letras, 2009. p. 78-79.

${ }^{15}$ MAGALHÃES JÚNIOR, Raimundo. Machado de Assis, vida e obra. v. 2. Rio de Janeiro: Record, 2008. p.182.

${ }^{16}$ As informações a respeito das publicações do ensaio estão em: SOUSA, José Galante de. Bibliografia de Machado de Assis. Rio de Janeiro: MEC-INL, 1955. p. 465-466. Não consta ali a referência à publicação em A Reforma, de Porto Alegre, feita pela professora Regina Zilberman, a quem agradeço. $\mathrm{O}$ Museu Hipólito José da Costa, de Porto Alegre, guarda uma coleção do jornal, mas o maço de jornais referente ao segundo semestre de 1873 foi perdido. A historiadora Luciana Fernandes Boeira teve acesso ao maço, antes de ele desaparecer, e gentilmente repassou fotografias digitais do ensaio no A Reforma de Porto Alegre.
} 
debates sobre a Lei do Ventre Livre. ${ }^{17}$ Apresentou-se assim: "Ou a reforma ou a revolução". Em Porto Alegre, A Reforma circulou de junho de 1869 até 1912. ${ }^{18}$ No Recife, no final da década de 1840, circulava um jornal com o mesmo nome, que Sodré afirma ter feito parte da imprensa liberal de esquerda ou extrema-esquerda.

Jean-Michel Massa assinalou que Machado frequentava a redação de $A$ Reforma. Isso ajuda a explicar por qual razão "Notícia" foi republicado pelo jornal no Rio e em Porto Alegre. ${ }^{19}$ Além disso, pela presença de artigos replicados, é certo que $A$ Reforma de Porto Alegre mantinha intercâmbio de artigos com os republicanos fluminenses, entre eles A República e A Reforma. ${ }^{20}$

Em resumo, a imprensa liberal formou o contexto primeiro de produção, circulação e leitura do ensaio machadiano - em parte, a imprensa liberal radical (salientem-se as diversas posições do universo liberal daquele período e as desavenças às vezes agudas entre elas, sobretudo a partir da Guerra do Paraguai, deflagrada no liberal Gabinete Furtado). Publicado originalmente em O Novo Mundo, "Notícia" repercutiu em seguida num dos jornais mais lidos do período, tanto no Rio quanto em Porto Alegre.

Mas não foi somente o ensaio a circular nesse grupo de periódicos. Tudo indica que diversos periódicos liberais do início dos anos 1870 - em que pesem suas singularidades - se valeram do prestígio e da relativa legitimidade de Machado, enquanto este teve seu nome disseminado e prestigiado, em resenhas, comentários, pequenas notas e notícias. Sirvam como ilustração do que se disse os seguintes

\footnotetext{
${ }^{17}$ SODRÉ, Nelson Werneck. História da imprensa no Brasil. Rio de Janeiro: Mauad, 1999. p. 214. Pode haver relações entre o jornal francês, surgido na Segunda República, La Réforme, e os A Reforma brasileiros. Charles Ribeyrolles, que, nos estudos de Massa (MASSA, Jean-Michel. A juventude de Machado de Assis: ensaio de biografia intelectual. São Paulo: Unesp, 2009.), ver nota 19, a seguir, e MAGALHÃES JÚNIOR, cit., é referido como um dos instrutores das posturas liberais do jovem Machado de Assis, chegou a editor de La Réforme, periódico que apoiou a república.

${ }^{18}$ Idem, p. 230.

${ }^{19}$ MASSA, Jean-Michel. A juventude de Machado de Assis, cit., p. 501. Massa também aponta, entre outras coisas, a importante relação pessoal entre o jovem Machado e Charles Ribeyrolles, exilado francês, ardoroso liberal, com quem Machado teria aprendido alguns dos ideais que possibilitaram a entrada em periódicos como Diário do Rio de Janeiro. Ver p. 187 e passim. Ver também MAGALHÃES JÚNIOR, cit., v.2, p. 95 e passim. Saliente-se que a informação de Massa está truncada. As fontes do pesquisador são os artigos publicados por Salvador de Mendonça em $O$ Imparcial, nos quais fica salientada a relação de Machado com liberais republicanos, em torno de diversos periódicos, sem contudo estar assinalada a presença de Machado na redação do jornal.
}

${ }^{20}$ MENDONÇA, Salvador de. Cousas de meu tempo. In: Revista do Livro, 1960. v. 20. p. 18-64. 
exemplos: em 29 de janeiro de 1870, A Reforma do Rio elogiou Falenas, obra de "verdadeiro poeta", o Machado de Assis, cuja "aptidão literária não se discute". Em 13 de fevereiro de 1870, uma nota elogiou o editor Garnier e o "primor e o castigado do estilo" dos Contos fluminenses, ao gosto dos melhores de Théophile Gautier e Gerard Nerval (este último, referido por Machado, em "Notícia da atual literatura brasileira", como um dos bons nomes da literatura francesa). ${ }^{21}$ Em 20 de maio de 1870, uma crônica geral comentou festa em homenagem ao general voluntário da pátria no Paraguai, Francisco Pinheiro Guimarães. Durante a efeméride, logo depois da execução do hino nacional, Furtado Coelho recitou obra encomiástica do "gentil poeta" Machado de Assis.

Merece discussão à parte - seguindo com os exemplos da inserção de Machado na imprensa liberal e da apropriação de seu prestígio e seus textos por ela - a carta a Francisco Otaviano, antes publicada em A República, que Salvador de Mendonça republicou no dia 23 de junho de 1871, comentando a atuação de Rossi como Hamlet. Trata-se de uma crítica ao público de "hotentotes", que, apesar dos empenhos da imprensa, deixou o teatro vazio. Os nomes da imprensa liberal aparecem entre aqueles que se esforçaram para divulgar a apresentação e "os fogos santos do patriotismo": Muzzio, Joaquim Serra (que se tornaria o principal redator de A Reforma), Guimarães Jr., Zaluar, além de Machado, Quintino, Pinheiro Guimarães, Alencar. ${ }^{22}$

Machado se inseriu no debate publicando no A Reforma de 20 de junho de 1871 uma carta a Salvador de Mendonça. Os editores enfatizaram-na por meio de nota de primeira página, na qual se lê que um dos "mais esperançosos escritores" brasileiros, o "ilustre" Machado de Assis, enviou ao jornal um escrito "elegante" e "bem pensado". E conclui: "Ao sr. Machado de Assis, nosso amigo e colega, agradecemos a escolha que fez de nossa folha para nela inserir seu artigo".

\footnotetext{
21 "Os livros de certa escola francesa, ainda que muito lidos entre nós, não contaminaram a literatura brasileira, nem sinto nela tendências para adotar as suas doutrinas, o que é já notável mérito. As obras de que falo foram aqui bem-vindas e festejadas, como hóspedes, mas não se aliaram à família nem tomaram o governo da casa. Os nomes que principalmente seduzem a nossa mocidade são os do período romântico; os escritores que se vão buscar para fazer comparações com os nossos - porque há aqui muito amor a essas comparações - são ainda aqueles com que o nosso espírito se educou, os Vítor Hugos, os Gautiers, os Mussets, os Gozlans, os Nervals" (OC, III, p. 1207).

${ }^{22}$ Por estranho que pareça o nome de Alencar, um monarquista conservador, figurar numa lista de nomes presentes na imprensa liberal, trata-se disso mesmo: A República publicou, no final de 1871 e início de 1872, o romance Til.
} 
A carta de Machado repercute a ideia de Mendonça de que Francisco Otaviano fora "ingrato" com as musas e que devia deixar um pouco a política de lado para vir socorrer os problemas da "academia", as dificuldades que Rossi vinha enfrentando. Machado elogia as representações do ator italiano e assinala com insistência a universalidade do "gênio", tanto de Rossi quanto de Shakespeare.

Os exemplos se sucedem, tanto em A Reforma do Rio quanto em A Reforma de Porto Alegre. Analisá-los demandará outro estudo, mas, para o momento e para os propósitos do que se apresenta, está caracterizada a inserção de Machado no ambiente da imprensa liberal, aliás, integrado por O Novo Mundo.

Estudo recente a respeito desse jornal indica que, embora impresso em Nova Iorque, contava no Brasil boa parte do público da tiragem de mais de oito mil exemplares. Artigos do jornal o apresentam como tentativa de divulgar no Brasil aspectos das instituições e do "progresso material" dos Estados Unidos. ${ }^{23} \mathrm{Com}$ isso, ajudaria o Brasil a se "livrar da religião, do Estado, da escravidão e do papel-moeda". ${ }^{24}$ Desde seu nome, contrapunha-se às concepções que viam na França, o velho mundo, o exemplo e o modelo para o Brasil.

Há, em diversos números do periódico, críticas à literatura francesa sua contemporânea. Num desses momentos, o Brasil é representado como um país que nada produzia de obras civilizadoras e religiosas (exceção feita aos livros de Direito e jurisprudência). Porém, a necessidade de obras civilizadoras não parecia ser sentida pelo povo, que, no juízo do redator (provavelmente José Carlos Rodrigues), parecia ser um povo sábio, de tal modo a agora poder se satisfazer apenas com romances e poesias. Em 24 de junho de 1872, Rodrigues se desculpa por não dar notícia das produções literárias brasileiras nem criticar as tendências dessa literatura, pela razão de faltar-lhe simpatia com as tendências literárias, ligadas demais à França. ${ }^{25}$

\footnotetext{
23 ASCIUTTI, Mônica Maria Rinaldi. Um lugar para o periódico O Novo Mundo. Dissertação de Mestrado. São Paulo: USP, 2010.

${ }^{24}$ O Novo Mundo, novembro, 1879.

${ }^{25}$ Para alguns exemplos, entre outros, de crítica aos romances franceses e suas traduções, ver: $O$ Novo Mundo, 24/10/1871, p. 7. "Literatura do dia", 23/02/1872. "O ensino das mulheres", 23/03/1872.
} 
$\mathrm{Na}$ exposição da linha editorial do jornal, dois campos de contradição do ensaio de Machado aparecem: a literatura francesa contemporânea e o papel da crítica para o estabelecimento de tendências saudáveis para a literatura. ${ }^{26}$

O que temos até aqui indica-nos dois pontos que vale a pena incluir nas discussões a respeito de "Notícia": (1) que o ensaio dialogou com - e em grande parte reforçou - as ideias do programa de O Novo Mundo. (2) Que o ensaio foi lido em periódicos liberais, todos eles antiescravistas, de tendências republicanas. Estando corretas, então quais as consequências dessas conclusões para a compreensão do processo de produção da escrita e das primeiras leituras de "Instinto de nacionalidade"?

3.

Talvez um contraste ajude-nos a criar uma perspectiva de análise. Em 1910, "Instinto de nacionalidade" abriu o volume de críticas de Machado, organizado por Mário de Alencar para a Garnier. Essa seleção seria reeditada na "Colleção dos Autores Celebres da Literatura Brasileira", também pela Garnier. ${ }^{27}$ Em 1921 e 1937, a Garnier e a Jackson, respectivamente, republicaram o ensaio. Em 1926, 1937, 1942, excertos dele circulavam em seletas, uma das quais com o título Paladinos da linguagem. ${ }^{28}$

Se, nos primeiros quinze anos de sua circulação, veículos da imprensa liberal se apropriaram do ensaio, depois da morte de Machado de Assis o texto foi canonizado em livros e mobilizado por outros discursos, o que alterou a maneira de interpretar seus pressupostos e hipóteses. Nesse ponto, gostaria de trazer um exemplo.

Em resenha, José Veríssimo apontou problemas na edição de 1910, uma parte dos quais considerava ser - acusação recorrente, há muitos anos - responsabilidade do tipógrafo francês, visto que a Garnier seguia imprimindo seus volumes em Paris. ${ }^{29}$

\footnotetext{
${ }^{26}$ ASCIUTTI, Mônica Maria Rinaldi. Um lugar para o periódico O Novo Mundo, cit., argumenta que Machado seguiu de perto a linha editorial do periódico.

${ }^{27}$ SOUSA, José Galante de. Bibliografia de Machado de Assis, cit., p. 116-117. Sousa estima que houve reedição, talvez em 1924, e, logo em seguida, outra reedição sem data precisa.

${ }^{28}$ Idem, p. 466.

${ }^{29}$ Ver: SCHAPOCHNIK, Nelson. Malditos tipógrafos. Anais do I Congresso Brasileiro sobre o Livro e História Editorial. Rio de Janeiro, 2004. Disponível em: <http://www.livroehistoriaeditorial.pro.br /pdf/nelsonschapochnik.pdf>. Acessado em 03/09/2013.
} 
Ao comentar o volume coligido por Mário Alencar, Veríssimo escreveu alguns parágrafos a respeito de "Instinto de nacionalidade". Argumentou que o escritor encarava os fenômenos literários sobretudo do ponto de vista da estética literária, o que não o impedia de descobrir e explicar as "condições sociais ou mesológicas" determinantes ou atuantes nesse fenômeno. Para Veríssimo, a testemunhar a respeito da capacidade de Machado para esse último tipo de crítica, estaria "o arguto e judicioso ensaio sobre o Instinto de nacionalidade na nossa literatura", no qual

[...] sem faltar à justiça antes fazendo-a rigorosa e boa, aos fundadores da nossa literatura nacional, apontava com segurança os pontos fracos ou duvidosos de certos conceitos literários, o que neles lhe parecia errado, aventando opiniões que então, em 1873, eram de todo novas. Ninguém, nem antes nem depois, estabeleceu mais precisa e mais simplesmente a questão do indigenismo na nossa literatura, nem disse coisas mais justas do indianismo e da sua prática. ${ }^{30}$

Entende-se a apologia ao "nosso maior escritor", mas quase tudo nas afirmações desse trecho é problemático. O Novo Mundo, para não falar em diversos outros jornais, veiculava textos com noções a respeito do indianismo e da literatura francesa (principalmente romances sensuais, de crimes, de adultério, ligados à expansão do mercado livreiro) que - em que pesem as diferenças - guardavam diversos paralelos com as ideias de Machado. O mesmo pode ser dito de noções como "cor local". ${ }^{31}$ Portanto, as opiniões de Machado não "eram de todo novas", sem prejuízo de sua acurácia e senso crítico.

Nesse sentido, Veríssimo contribuiu para sedimentar uma prática frequente nas avaliações da literatura machadiana, aliás potencializada quando a leitura ocorre tendo livros como suporte: trata-se de isolar Machado do conjunto de práticas dos intelectuais fluminenses, congratulando-o por ser uma exceção, uma subjetividade ética incólume

\footnotetext{
${ }^{30}$ VERÍSSIMO, José. Machado de Assis crítico. In: Letras e literatos: estudinhos críticos da literatura do dia (1912-1914). Rio de Janeiro: José Olympio, 1936. p. 80-81.

${ }^{31}$ Em 23 de julho de 1872, O Novo Mundo comenta artigo no qual Joaquim Nabuco defendia, contra Alexandre Herculano, que a poesia de Gonçalves Dias tinha "muita cor local", mas isso não era suficiente para garantir sua originalidade. Não falta a referência a Shakespeare (bretão, romano e mouro), lugar comum no período. Em 23 de agosto de 1872, no artigo "Longfellow, o poeta", William Cullen Bryant é criticado em comparação com Longfellow, pois os poemas do primeiro, "ricos como são da cor local americana, são muito contemplativos demais, e tem pouca ternura ou paixão para nos agradar".
} 
ou absolutamente consciente dos limites da época, o máximo de consciência possível, em meio a um mar de decadência, ignorância e tacanhez. Essas qualidades se estendem aos escritos de Machado, naturalizados como produção de um superindivíduo, intocado pelos hábitos mentais dos seus coetâneos, intocado pela qualidade adversa do ambiente cultural brasileiro, intocado mesmo pela indeterminação da história. Essa unidade, coerência e autonomia absoluta projetada na figura de Machado aponta flagrante mitificação, à qual cabe contrapor discussões e pesquisas.

Se "Instinto de nacionalidade" foi produzido e - num primeiro momento - lido na imprensa liberal, torna-se necessário em algum momento levar isso em conta, o que não significa remeter a um Machado mais verdadeiro do que o de Veríssimo. Trata-se, sim, de estabelecer perspectivas e espaços de análise que tentem colaborar para compor, tanto com a perspectiva de Veríssimo quanto com outras, maior densidade em meio às contradições do campo de estudos machadianos. A tarefa é enxergar conflitos, isto é, a história das representações e práticas envolvidas na produção da leitura de "Instinto de nacionalidade", no lugar da placidez consagradora do nosso mestre paladino do idioma e da literatura.

Em resumo, a perspectiva inteligente apresentada pelo ensaio deve parte de sua agudeza também ao diálogo de Machado com os seus coetâneos, muitos dos quais vinham há anos antecipando e ajudando a aprofundar o problema. Rápidos exemplos podem ajudar a entender a presença dos temas do ensaio na cultura letrada brasileira.

Um primeiro exemplo: Joaquim Noberto de Sousa e Silva discutiu o problema do papel dos indígenas na construção da civilização nacional. Para ele, os primeiros poetas brasileiros deveriam ser procurados nos povos autóctones. Em contraposição, João Manoel Pereira da Silva duvidava da possibilidade de os autóctones produzirem literatura, pois sequer civilização possuíam. ${ }^{32}$

\footnotetext{
${ }^{32}$ Ver: AUGUSTI, Valéria. Trajetórias de consagração: discursos da crítica sobre o romance no Brasil oitocentista. Campinas: Mercado de Letras, 2010. p. 22; e também: MOREIRA, Maria Eunice; ZILBERMAN, Regina. O berço do cânone. Porto Alegre: Mercado Aberto, 1998.
} 
Outro exemplo: a crítica a romances franceses contemporâneos era lugar comum em O Novo Mundo, que os representava - "literatura abominável de matar o tempo" - como um dos empecilhos para o progresso do Brasil. ${ }^{33}$

Terceiro exemplo: algumas classificações de retores a respeito do que era ou deveria ser um romance parecem dialogar com muitas das classificações dadas por Machado nos paratextos de seus próprios romances e em resenhas críticas. Entre tantas, veja-se a de Manoel da Costa Honorato, que em 1879 definia o romance como "quadro da vida moral". 34

Último exemplo: Francisco Sotero dos Reis publicou, em 1864, no Diário do Rio de Janeiro, uma sucessão de lições de um curso de literatura oferecido no Instituto de Humanidades do Maranhão. Reis pretendia que a literatura lidasse com o sublime, razão pela qual repreendeu em alguns românticos a "exageração na cor local". ${ }^{35}$

Em muitos aspectos, "Instinto de nacionalidade" evoca repertórios caros aos formuladores das concepções sobre literatura brasileira pelo menos desde os anos 1830 (lembremos que é de 1838 a fundação do Instituto Histórico e Geográfico Brasileiro, de cuja revista o que nos ficou da biblioteca de Machado contém 42 exemplares, cobrindo o período de 1839 a 1875), num dos gêneros textuais prediletos desses formuladores, isto é, o panorama histórico, a "notícia" ou a "memória". ${ }^{36}$ Até mesmo a ideia de que a cor local não se resumia a uma atitude descritiva, mas deveria ajudar a compor entre outros fatores o íntimo da obra, à primeira vista tão original, talvez se trate de um topos crítico da década anterior, bem sabido, entre outros, pelos frequentadores do Instituto de Humanidades do Maranhão.

Sintetizando, parece que alguns dos valores e temas centrais do ensaio eram lugares-comuns na imprensa liberal e em O Novo Mundo: o clamor por uma crítica

\footnotetext{
33 ASCIUTTI, Mônica Maria Rinaldi. Um lugar para o periódico O Novo Mundo, cit., escreveu: "a presença do ensaio crítico de Machado de Assis afirmou que a sua publicação em $O$ Novo Mundo se conformava ao caráter do periódico, ideologicamente distante do universo europeu que, até então, perfazia as bases referenciais dos escritores brasileiros" (p. 14). Ver também O Novo Mundo, 23 de fevereiro de 1872.

${ }^{34}$ AUGUSTI, Valéria. Trajetórias de consagração, cit., p. 72.

${ }^{35}$ Diário do Rio de Janeiro, 19/12/1864, p.2.

${ }^{36}$ ROCHA, João Cezar de Castro. Machado de Assis leitor (autor) da Revista do Instituto Histórico e Geográfico Brasileiro. In: JOBIM, José Luís (Org.). A biblioteca de Machado de Assis. Rio de Janeiro: Academia Brasileira de Letras; Topbooks, 2001. p. 324.
} 
judiciosa, a condenação à cor local como critério prevalecente de avaliação da literatura, a desaprovação dos romances franceses do momento.

Esses valores - que não exaurem as diversas hierarquias pressupostas pelo olhar machadiano à literatura brasileira, nem menos ainda as perspectivas possíveis no sistema literário do período - deixam notar uma posição relacionada com outras posições, que ainda pouco conhecemos, na luta pela classificação do que era e do que deveria ser a literatura praticada no Brasil. Seria empobrecedor caso nos ativéssemos somente a essa representação para estabelecer os aspectos da literatura lida e produzida no Brasil daquele período. Vale a pena duvidar da completude e onisciência às vezes emprestadas à voz machadiana, vindo a considerar, quem sabe, alguns dilemas, descontinuidades, dúvidas e conflitos que compõem as forças sociais empenhadas na produção e leitura de "Instinto de nacionalidade", um ensaio que, num primeiro momento, parece ter sido um artigo da e na imprensa liberal. Nesse sentido, ainda há um horizonte de pesquisa a explorar para compreendermos não facetas do ensaio "em si", mas as construções sociais e históricas de "Instinto de nacionalidade" como objeto privilegiado dos debates a respeito do que deve ou não deve ser a literatura, do que deve ou não deve ser a análise de obras literárias.

$$
* * *
$$

\section{Referências:}

ASCIUTTI, Mônica Maria Rinaldi. Um lugar para o periódico O Novo Mundo. Dissertação de Mestrado. São Paulo: USP, 2010.

ASSIS, Machado de. Obra completa em quatro volumes. v. 3. Rio de Janeiro: Nova Aguilar, 2008.

AUGUSTI, Valéria. Trajetórias de consagração: discursos da crítica sobre o romance no Brasil oitocentista. Campinas: Mercado de Letras, 2010.

JOBIM, José Luís (Org.). A biblioteca de Machado de Assis. Rio de Janeiro: Academia Brasileira de Letras: Topbooks, 2001.

MAGALHÃES JÚNIOR, Raimundo. Machado de Assis, vida e obra. v. 2. Rio de Janeiro: Record, 2008.

MASSA, Jean-Michel. A juventude de Machado de Assis: ensaio de biografia intelectual. São Paulo: Unesp, 2009. 
MOREIRA, Maria Eunice; ZILBERMAN, Regina. O berço do cânone. Porto Alegre: Mercado Aberto, 1998.

MENDONÇA, Salvador de. Cousas de meu tempo. In: Revista do Livro, 1960, v. 20, p. $18-64$.

ROUANET, Sergio Paulo (Org. e Coord.), Correspondência de Machado de Assis: tomo II, 1870-1889. Rio de Janeiro: Academia Brasileira de Letras, 2009.

SCHAPOCHNIK, Nelson. Malditos tipógrafos. Anais do I Congresso Brasileiro sobre $o$ Livro e História Editorial. Rio de Janeiro, 2004. Disponível em: http://www.livroehistoriaeditorial.pro.br/pdf/nelsonschapochnik.pdf. Acessado em 03/09/2013.

SODRÉ, Nelson Werneck. História da imprensa no Brasil. Rio de Janeiro: Mauad, 1999.

SOUSA, José Galante de. Bibliografia de Machado de Assis. Rio de Janeiro: MEC-INL, 1955.

VERÍSSIMO, José. Machado de Assis crítico. In: Letras e literatos: estudinhos críticos da literatura do dia (1912-1914). Rio de Janeiro: José Olympio, 1936.

ZILBERMAN, Regina. Almeida Garrett e o cânone romântico. Via Atlântica, n. 1, março, 1997, p. 54-65.

Periódicos:

Diário do Rio de Janeiro.

A Reforma, órgão democrático.

A Reforma, órgão do partido liberal.

O Novo Mundo.

Revue des Deux Mondes.

www.gallica.fr

http://hemerotecadigital.bn.br/

Atilio Bergamini é pós-doutorando no projeto temático "A circulação transatlântica dos impressos" (Fapesp / Iel-Unicamp). Tem doutorado e mestrado em Literatura Brasileira pela UFRGS. Sua tese discute as relações entre a escrita ficcional de Machado de Assis e os projetos editoriais do Jornal das Famílias e da Revista Brasileira. Email: <atiliobergamini@gmail.com>.

Recebido: 15.09.2013

Aprovado: 18.11.2013 